\title{
Empathy levels among first year Malaysian medical students: an observational study
}

This article was published in the following Dove Press journal:

Advances in Medical Education and Practice

16 May 2014

Number of times this article has been viewed

Brett Williams'

Sivalal Sadasivan ${ }^{2}$

Amudha Kadirvelu ${ }^{2}$

Alexander Olaussen'

'Department of Community

Emergency Health and Paramedic

Practice, Melbourne, Australia; ${ }^{2}$ Jeffrey

Cheah School of Medicine and Health

Sciences, Sunway Campus, Selangor,

Malaysia
Correspondence: Brett Williams Department of Community Emergency Health and Paramedic Practice, Faculty of Medicine, Nursing and Health Sciences, Monash University Peninsula Campus, PO Box 527, McMahons Road, Frankston, Melbourne, Victoria 3199, Australia

Tel +6I 399044283

Fax +61399044168

Email brett.williams@monash.edu
Background: The literature indicates that medical practitioners experience declining empathy levels in clinical practice. This highlights the need to educate medical students about empathy as an attribute early in the academic curriculum. The objective of this study was to evaluate year one students' self-reported empathy levels following a 2-hour empathy workshop at a large medical school in Malaysia.

Methods: Changes in empathy scores were examined using a paired repeated-measures $t$-test in this prospective before and after study.

Results: Analyzing the matched data, there was a statistically significant difference and moderate effect size between mean empathy scores before and 5 weeks after the workshop $(112.08 \pm 10.67$ versus 117.93 $\pm 13.13, P<0.0001, d=0.48)$ using the Jefferson Scale Physician Empathy (Student Version).

Conclusion: The results of this observational study indicate improved mean self-reported empathy scores following an empathy workshop.

Keywords: empathy, medical students, Malaysia

\section{Introduction}

Empathy is one of medicine's cornerstones. Not only does empathy encompass an ability to recognize and understand the perspective of the patient, but also requires communication appreciation in return. ${ }^{1-3}$ There are a number of reasons why empathy is important in medicine.

Firstly, increasing attention on client-centered care requires clinicians to keep abreast of the social aspects of medicine. This is especially the case in an era of informatics and technologies where human interaction and perspectives can be often overlooked when using computers. ${ }^{4}$ Despite these challenges, empathy is still viewed by patients as one of the most important traits of a physician. ${ }^{5}$ There is empirical evidence that empathetic behavior favorably impacts patient satisfaction, ${ }^{6-10}$ emotional distress, ${ }^{9}$ and enablement. ${ }^{11}$

Secondly, empathy improves health outcomes. ${ }^{12-14}$ Patients with empathetic doctors have been shown to have fewer complications from diabetes, ${ }^{12,13}$ a shorter duration of symptoms with the common cold, ${ }^{14}$ and have reduced stress and anxiety with doctor visits. ${ }^{15,16}$ Having an empathetic clinician also improves patients' recall ${ }^{6,7}$ and compliance, ${ }^{7,8}$ and helps them to follow recommendations more readily. ${ }^{12}$

Thirdly, empathetic doctors are more likely to get referrals, ${ }^{17}$ operate with increased efficiency, ${ }^{18}$ and be less likely to "burn out". ${ }^{19}$ Ultimately, empathy ensures trust and allows symptoms to be unmasked, thereby improving diagnosis, improving patient adherence with medical directions, and ensuring better care. ${ }^{20}$ 
Empathy is often confused with sympathy. ${ }^{21,22}$ Some argue that sympathy represents feelings and empathy represents thinking, ${ }^{20,23}$ while others ${ }^{16}$ challenge this notion, suggesting that sympathy and empathy require compassion and passion, respectively. However, it is suggested that empathy is more altruistic, objective, and intellectual, and less innate, spontaneous, and energy-consuming when compared with sympathy. ${ }^{23}$ Conversely, sympathy is more primitive, emotionally driven, and egoistic. ${ }^{23}$ Knowing, and indeed applying, these differences is important because patients want to be understood rather than pitied. For research and practical purposes, a universal definition is needed to be able to review the relevant studies collectively.

In 2001, a systematic review by Di Blasi et a $1^{18}$ concluded that the effects of empathetic behavior were inconsistent. Since then, more empirical evidence has emerged, and increased the body of knowledge on empathy. Two landmark papers ${ }^{12,13}$ demonstrated improved glucose control in diabetic patients treated by empathetic doctors. Both papers assessed empathy in clinicians using the Jefferson Scale of Empathy (JSE). The first study by Hojat et $\mathrm{l}^{13}$ grouped doctors ( $\mathrm{n}=891$ ) according to empathy score (low, moderate, or high). After 3 years, their patients' glycated hemoglobin and low-density lipoprotein cholesterol levels were measured. Over half $(56 \%)$ of the patients treated by doctors with high empathy had favorable glycated hemoglobin levels $(<7.0 \%)$ versus $40 \%$ of those under care of a doctor with low empathy $(P<0.01)$. Control of low-density lipoprotein cholesterol showed a similarly significant favorable correlation (59\% versus $44 \%$, $z=3.8, P<0.01)$. Logistic regression showed that the odds ratio for improved control between physicians with low and high empathy levels increased by $80 \%$.

The second and larger $(n=20,961)$ study by Del Canale et $\mathrm{al}^{12}$ assessed the impact of empathy on the risk of acute metabolic complications from diabetes mellitus. This outcome measure was deliberately chosen because primary care physicians have a greater role in prevention of these types of complications than specialists and such complications require hospitalization, enabling a more accurate picture of incidence. This study reported that patients treated by highly empathetic doctors had four acute complications per 1,000 patients, which was significantly lower than the 7.1 and 6.5 complications per 1,000 reported for patients treated by doctors with moderate or low empathy scores, respectively. Logistic regression analysis showed that the odds of acute metabolic complications decreased by $41 \%$ if the treating physician had high empathy rather than low empathy $(P<0.01)$.
Hojat et $\mathrm{al}^{13}$ and Del Canale et a ${ }^{12}$ concluded that empathy is a vital element in patient care. Given the importance of empathy, constant renewal of curriculum activities is being undertaken; however, questions are often raised as to whether empathy can actually be taught. Perhaps a more pertinent question is whether empathy can be measured or assessed.

Despite these questions, empathy is certainly a complex construct that can be influenced by multiple factors (ie, clinical exposure and professional socialization), as highlighted by the frequently reported decrease in empathy during medical training. ${ }^{21,24-31}$ It is concerning that this negative trend continues after graduation and into professional practice. ${ }^{32-34}$ Two studies ${ }^{32,34}$ followed 61 and 47 doctors during their internship year and noted an increase in stress, anger, and sleep deprivation, and decreasing levels of empathy.

Reassuringly, there are also studies demonstrating an increase in empathy levels with the passage of time. ${ }^{35-39}$ However, these studies were done in non-English-speaking countries, and relied on translated versions of the JSE. Plausible explanations for this are grounded in the cohort effect and cultural differences that the US-derived JSE may be unable to discriminate.

Putting this into perspective, a review of eleven studies by Colliver et $\mathrm{al}^{40}$ in 2010 found that, on a seven-point Likert scale, the decrease in empathy was only -0.2 between the first year of training and graduation. Therefore, these authors argued that the concern surrounding decreased empathy was not warranted. Further, it has been noted that students and interns with decreasing empathy levels only approach the population norm. ${ }^{26,32}$ Recent evidence ${ }^{41}$ also suggests that this decrease could just be due to a shift in focus between the four components of empathy (ie, emotional, moral, cognitive, behavioral), as described by Morse et al. ${ }^{42}$

Whether there is a decline in empathy or not, there are barriers to empathetic behavior. Suggested explanations for this include emotional exhaustion, ${ }^{5}$ a highly demanding work environment, ${ }^{43}$ unawareness or lack of belief in the importance of empathy, ${ }^{44}$ or just cynicism. ${ }^{45}$ However, as Larson and $\mathrm{Yao}^{43}$ highlight, the work of a clinician involves some degree of "emotional labor". The best way to overcome these barriers is by education and training. If this worrisome decline is present, the finding by Fernández-Olano et $\mathrm{al}^{46}$ that students are more likely to show improvement in empathy following training than residents ( $75 \%$ versus $56.4 \%, P=0.04$ ) is reassuring.

Empathetic behaviors ranges coexist with all forms of communication, eg, posture and tone of voice. ${ }^{13}$ Therefore, it is not surprising that different educational approaches exist 
for promoting empathetic behavior. Examples that have been investigated include reflective practice, ${ }^{47}$ interview training, ${ }^{46}$ and even use of specific words and sentences. ${ }^{2}$ The role of acting classes in the medical curriculum is debatable, ${ }^{48}$ although there is some research showing that role play makes students more empathetic. ${ }^{27}$

This paper reports an observational study examining whether a workshop focused on empathy can improve selfreported empathy levels in first year Malaysian medical students.

\section{Materials and methods Workshop design and delivery}

This study used a before and after repeated-measures design. In March 2013, a 2-hour interactive empathy workshop was held for first year medical students during their 3-day orientation to the medicine program. The aim of the workshop was to enhance and promote awareness of empathy. Attendance at the orientation program was compulsory for all students, and included other topics, such as professionalism, health and well-being, resilience, and life as a medical student. The empathy workshop was interactive and based on a 20-minute DVD simulation involving a pregnant patient who suffered a stroke. The case was specifically developed to provide participants with an opportunity to understand empathy better in a clinical context. This hypothetical patient was suffering from acute dysphasia, making communication difficult, and the patient's husband was worried about radiological procedures. Activities were based on work in small groups and group presentations. Participants examined the medical definitions of empathy and the semantics of empathy versus other terms, such as sympathy, affinity, and caring. Participants were also asked to consider the following four questions as they watched the DVD:

- What do you think the needs of the patient were?

- Do you think the patient's needs were met in this clinical interaction?

- What empathetic behaviors did you see or observe in this scenario?

- What was the impact of this behavior on interaction between the patient and doctor?

\section{Participants}

Participating students were enrolled in year one of the medical degree at JC School of Medicine and Health Sciences, Sunway, Malaysia. A total of 122 students were eligible for inclusion in the study, ie, were enrolled full time and consented to take part in the study.

\section{Instruments used}

The study used a standardized self-reporting scale, ie, the Jefferson Scale of Physician Empathy (Student Version) JSPE-S, which is a self-report measure of medical students' attitudes towards empathy. The JSPE-S is presented to students in English and does not require any translation. It is a 20 -item instrument using a seven-point Likert scale (1, strongly disagree; 7 , strongly agree), with ten items that are reverse-scored. When originally developed, the JSPE-S was found to be valid and reliable. ${ }^{3}$ A short demographic questionnaire was included.

\section{Procedures}

Prior to holding the empathy workshop, students were invited to participate on a voluntary basis. They were provided with an explanatory statement and informed that participation was voluntary and matched by identification for follow-up. The questionnaires took students approximately 10 minutes to complete, and consent was implied by their completion and submission. The participants were followed up 5 weeks later, when they were informed about the study again and asked to complete a follow-up questionnaire.

\section{Data analysis}

SPSS version 20.0 (SPSS Inc., Chicago, IL, USA) was used for data storage, tabulation, and generation of descriptive and inferential statistics. Descriptive statistics including means, standard deviations and confidence intervals were used to summarize the demographic data. A paired repeatedmeasures $t$-test was used to compare before and after results, and chi-square $\left(\chi^{2}\right)$ tests were used to explore demographic relationships and empathy levels. All tests were two-tailed, with the results considered to be statistically significant if the $P$-value was $<0.05$. Effect sizes $(d)$ were also calculated to quantify the differences between mean scores.

\section{Results}

\section{Participant demographics}

A total of 122 first year medical students completed the before and after questionnaires, giving a response rate of $100 \%$. The median age was 20 (17-22) years, with a preponderance of women $(55.7 \%)$ and students of Chinese ethnicity (70\%). $\chi^{2}$ tests were used to determine whether different student characteristics influenced empathy levels, and no statistically significant relationship was found between any demographic variable and empathy score. A more detailed description of the students is given in Table 1 . 
Table I Participant demographic characteristics

\begin{tabular}{|c|c|c|}
\hline & $\mathbf{n}$ & $\%$ \\
\hline \multicolumn{3}{|l|}{ Sex } \\
\hline Male & 54 & $44.3 \%$ \\
\hline Female & 68 & $55.7 \%$ \\
\hline \multicolumn{3}{|c|}{ Are either of your parents a medical doctor? } \\
\hline Yes & 21 & $17.2 \%$ \\
\hline No & 101 & $82.8 \%$ \\
\hline \multicolumn{3}{|c|}{ Are you the eldest child in your family? } \\
\hline Yes & 49 & $40.2 \%$ \\
\hline No & 73 & $59.8 \%$ \\
\hline \multirow{2}{*}{\multicolumn{3}{|c|}{$\begin{array}{l}\text { Have you cared for a person with a permanent } \\
\text { disability in your family, now or in the past? }\end{array}$}} \\
\hline & & \\
\hline Yes & 15 & $12.3 \%$ \\
\hline No & 107 & $87.7 \%$ \\
\hline \multicolumn{3}{|c|}{ Are you an international student? } \\
\hline Yes & 11 & $9 \%$ \\
\hline No & 111 & $91 \%$ \\
\hline \multicolumn{3}{|c|}{ What ethnic group do you belong to? } \\
\hline Chinese & 86 & $70.5 \%$ \\
\hline Indian & 23 & $18.9 \%$ \\
\hline Other & 13 & $9.8 \%$ \\
\hline \multicolumn{3}{|c|}{ What is your religious denomination? } \\
\hline Christian & 43 & $35.2 \%$ \\
\hline Buddhist & 51 & $41.8 \%$ \\
\hline Islamic & 5 & $4.1 \%$ \\
\hline Hindu & 13 & $10.7 \%$ \\
\hline Other & 10 & $8.2 \%$ \\
\hline
\end{tabular}

The mean JSPE-S score for the group was $112.08 \pm 10.67$ before attending the workshop, and increased significantly to $117.93 \pm 13.13$ after the workshop $(P<0.0001, d=0.48)$. A full distribution of results at the item level is shown in Table 2 . No difference in empathy levels was found between males and females ( $P=0.06$ before and $P=0.12$ after). However, females were more likely to be empathetic after the workshop, showing an increase in empathy scores from 110.5 to 119.6 ( $P=0.006, d=54)$, unlike male students, who were influenced by the workshop to a lesser degree (score improvement from 114 to $115.8, P=0.86$ ).

The internal consistency of the JSPE-S was measured using Cronbach's alpha which was $\alpha=0.70$ for the 20 items before and $\alpha=0.83$ after the workshop, indicating adequate internal reliability. Whether different student characteristics influence empathy levels was examined using $\chi^{2}$ tests for association, and no statistically significant difference was found.

\section{Discussion}

This observational study describes self-reported empathy levels in first year medical students in Malaysia before and after a 2-hour workshop on empathy. The results indicate that empathy levels improved significantly in the cohort, albeit mostly in female students, after the workshop. Whether the workshop was responsible for this increased level of empathy is difficult to determine, but previously published workshopbased activities have also suggested an improvement, ${ }^{22}$ indicating possible benefits from this form of teaching and learning.

Our findings are important in trying to understand the multidimensional construct of empathy in Malaysian medical students in a cross-cultural setting. Further, while there are well understood issues in the testing of empathy, ${ }^{49}$ the JSE has been shown to be a superior and valid self-reported predictor of long-term empathy levels. ${ }^{50}$ Our research adds to the body of knowledge on the JSE, particularly the version measuring empathy in medical students.

Our results 5 weeks after the workshop indicate a statistically significant before and after effect. This finding is consistent with that of other observational studies. For example, an Australian study by Winefield and Chur-Hansen ${ }^{51}$ found a similar age and sex distribution in 107 first year medical students when empathy testing was done prior to didactic lectures, videotapes, and workshops $(2 \times 1.5$ hours $)$ in groups of $10-12$ students with actors as patients. Although their study did not use the JSPE-S, improvement was seen in empathy levels, particularly in female students. Although longer-term follow-up was not undertaken, these findings highlight an area for further examination.

The JSE, which provides the theoretical basis for the JSPE-S (currently translated into 42 languages), ${ }^{52}$ has been tested in a range of cultural and linguistic settings. In nine identified studies, Cronbach's alpha ${ }^{53}$ was found to range from 0.74 to 0.90 , confirming good/excellent internal consistency. ${ }^{23,36,38,54-57}$ This is consistent with our post workshop Cronbach's alpha of 0.83 , suggesting that the JSPE-S is reliable in Malaysian students.

We postulate that the distinctive cultural situation that exists in Malaysia may have contributed to empathy levels in our students. In Malaysia, there are three major races, ie, Malay (60\%), Chinese (30\%), and Indian (5\%), which have different faiths, ie, Islam, Buddhism, and Hinduism, respectively. Of note is that this racial composition was not reflected in our medical students, of whom $70.5 \%$ were Chinese, $18.9 \%$ were Indian, and $0.25 \%$ were Malay. Religious tolerance is emphasized in Malaysia, and children are brought up to respect other faiths and encouraged to reflect on how another person might feel if they committed an act that was in conflict with that person's religious beliefs. Apart from this, actions by one group that impinge on another group's religious beliefs cause outrage in affected communities and the insensitivity of the people involved 
Table 2 Mean item-level comparisons before and after (5 weeks)

\begin{tabular}{|c|c|c|c|c|}
\hline Item & $\begin{array}{l}\text { Pre test } \\
\text { mean (SD) }\end{array}$ & $\begin{array}{l}\text { Post test } \\
\text { mean (SD) }\end{array}$ & $\mathrm{Cl}(95 \%)$ & $P$-value \\
\hline $\begin{array}{l}\text { Physician's understanding of the feelings of the patient and family } \\
\text { does not influence medical or surgical treatment }\end{array}$ & $5.22(1.75)$ & $6.09(1.46)$ & $-1.23-0.505$ & 0.017 \\
\hline Patients feel better when their physician understands their feelings & $6.61(1.06)$ & $6.67(0.88)$ & $-0.257-0.143$ & 0.000 \\
\hline $\begin{array}{l}\text { It is difficult for a physician to view things from the patient's } \\
\text { perspective }\end{array}$ & $4.77(1.31)$ & $4.98(1.41)$ & $-0.520-0.110$ & 0.074 \\
\hline $\begin{array}{l}\text { Understanding body language is as important as verbal } \\
\text { communication in the physician-patient relationship }\end{array}$ & $6.06(1.32)$ & $6.63(0.91)$ & $-0.836-0.311$ & 0.538 \\
\hline $\begin{array}{l}\text { A physician's sense of humor contributes to a better clinical } \\
\text { outcome }\end{array}$ & $5.18(1.41)$ & $5.55(1.37)$ & $-0.635-0.103$ & 0.000 \\
\hline $\begin{array}{l}\text { People are different, so it is difficult to see things from patients' } \\
\text { perspectives }\end{array}$ & $4.05(1.58)$ & $4.20(1.40)$ & $-0.519-0.207$ & 0.396 \\
\hline Patients' emotions is not important in history-taking & $6.20(1.13)$ & $6.56(1.00)$ & $-0.630-0.090$ & 0.976 \\
\hline $\begin{array}{l}\text { Paying attention to patients' experiences does not influence } \\
\text { treatment outcomes }\end{array}$ & $5.93(1.26)$ & $6.33(1.26)$ & $-0.706-0.080$ & 0.625 \\
\hline $\begin{array}{l}\text { Physicians should try to put themselves in the patient's position } \\
\text { when caring for them }\end{array}$ & $6.34(0.95)$ & $5.98(1.54)$ & $0.064-0.64 I$ & 0.009 \\
\hline $\begin{array}{l}\text { Patients value a physician's understanding of their feelings, and this is } \\
\text { therapeutic in its own right }\end{array}$ & $5.76(1.22)$ & $5.87(1.75)$ & $-0.507-0.294$ & 0.275 \\
\hline $\begin{array}{l}\text { Patients' illnesses can be cured only by medical or surgical treatment; } \\
\text { therefore, a physician's emotional involvement does not have a } \\
\text { significant role in treatment }\end{array}$ & $5.90(1.48)$ & $6.29(1.17)$ & $-0.726-0.043$ & 0.895 \\
\hline $\begin{array}{l}\text { Asking patients about what is happening in their personal lives is not } \\
\text { helpful in understanding their physical complaints }\end{array}$ & $6.04(1.23)$ & $6.28(1.28)$ & $-0.579-0.104$ & 0.090 \\
\hline $\begin{array}{l}\text { Physicians should try to understand what is going on in their patients' } \\
\text { minds by paying attention to nonverbal cues and body language }\end{array}$ & $5.84(1.39)$ & $6.28(1.42)$ & $-0.792-0.093$ & 0.662 \\
\hline Emotion has no place in the treatment of medical illness & $6.20(1.25)$ & $6.38(1.08)$ & $-0.462-0.101$ & 0.315 \\
\hline $\begin{array}{l}\text { Empathy is a therapeutic skill without which the physician's success } \\
\text { is limited }\end{array}$ & $5.60(1.53)$ & $6.07(1.62)$ & $-0.840-0.094$ & 0.162 \\
\hline $\begin{array}{l}\text { Physician's understanding of the emotional status of their patients, } \\
\text { as well as that of their families, is an important component of the } \\
\text { physician-patient relationship }\end{array}$ & $5.99(1.33)$ & $6.55(0.81)$ & $-0.825-0.290$ & 0.333 \\
\hline $\begin{array}{l}\text { Physicians should try to think like their patients in order to render } \\
\text { better care }\end{array}$ & $5.58(1.32)$ & $5.7 I(1.7 I)$ & $-0.465-0.203$ & 0.003 \\
\hline $\begin{array}{l}\text { Physicians should not allow themselves to be influenced by strong } \\
\text { personal bonds between patients and their family members }\end{array}$ & $2.95(1.59)$ & $3.15(1.83)$ & $-0.589-0.196$ & 0.042 \\
\hline $\begin{array}{l}\text { I do not enjoy reading nonmedical literature and have no } \\
\text { involvement with the arts }\end{array}$ & $5.56(1.72)$ & $5.77(1.43)$ & $-0.530-0.104$ & 0.000 \\
\hline $\begin{array}{l}\text { I believe that empathy is an important therapeutic factor in medical } \\
\text { treatment }\end{array}$ & $6.30(1.10)$ & $6.60(1.03)$ & $-0.543-0.047$ & 0.080 \\
\hline
\end{tabular}

Abbreviations: $\mathrm{Cl}$, confidence interval; $\mathrm{SD}$, standard deviation.

continues to be highlighted in the media, and also politicized. Formal classes aimed at inculcating good moral values are now part of the high school curriculum.

Asian culture as a whole has a tradition of tolerance and understanding, service to humanity, and respecting the rights and feelings of others. Similarly, religions like Hinduism and Buddhism (53\% of our students were of these faiths) include service above self, having sympathy for the sick and suffering, and helping to alleviating the woes of the less fortunate among their tenets.

All these factors may have contributed to our students' baseline empathy levels being possibly different from those in more homogeneous student populations in other countries. Hong et al have attributed differences in empathy levels between Western and Asian students to cultural differences. ${ }^{37}$ Moreover, Kataoka et al point out that the Japanese prefer their doctors to be calm and unemotional, whereas there is an expectation among Malaysian patients that doctors should function as family counselors and advise them on a range of issues, often unrelated to their illness, and are quite happy for their doctors to adopt a paternalistic role. ${ }^{36}$

We found no statistically significant difference in empathy scores between males or females before or after the workshop intervention, although self-reported empathy levels in the 
female cohort increased by a mean of 9.1 versus 1.7 in males. The mean difference in empathy scores before and after for females was statistically significant at $P=0.006$. Higher scores in females have been reported in a number of international studies. . $21,23,25,30,35,36,38,46,56,58-60$ Some authors speculate that this difference may be due to women having a greater capacity for empathetic communication, for providing support that is more emotional rather than rational, and for spending more time with their patients than their male counterparts.

Differences in outlook and perception between males and females may stem from the influence of culture and religion; females are expected to take on the responsibilities of nurturing and caring throughout their lives, beginning with caring for their siblings, moving on to caring for their husbands and children, and then their parents and in-laws. Women are expected to conform to these societal norms, and noncompliance would risk them being branded as unfilial daughters or unfit wives or daughters-in law.

However, there are a number of studies that have not found significant differences between males and females, ${ }^{55,57,61}$ and it has been suggested that this sex difference does not hold in the real-life setting. ${ }^{56}$ Further work in this area might include a mixed methodological perspective when attempting to unravel this complex phenomenon.

The possibility and feasibility of teaching empathy has been debated in the literature. Given that other observationalbased studies have shown an improvement, ${ }^{22}$ and that students are more amenable to change than residents, ${ }^{46}$ education on empathy would not necessarily be futile, and even overcome some of the identified barriers towards empathic behavior and improve patient health, particularly in primary care settings. Whether these workshop-based activities can sustain empathy over the longer term is a critical question posed now by a number of leading scholars. ${ }^{62,63}$

\section{Limitations}

This study has a number of limitations. First, its findings are from one tertiary institution, thereby limiting its generalizability. Second, self-reported measures have inherent respondent bias and in no way reflect what might occur in actual clinical practice. Third, the lack of a control group and randomization limited our ability to control for confounding variables. Longerterm follow-up is needed to determine whether the observed changes in empathy are transient or durable over time.

\section{Conclusion}

This study found improved mean self-reported empathy scores following an empathy workshop. These results suggest that similar educational activities may help to improve empathy in medical students.

\section{Acknowledgments}

The authors thank Professor Mohammadreza Hojat for his helpful comments on an early draft of this paper and all students who participated in this research.

\section{Disclosure}

The authors report no conflicts of interest in this work.

\section{References}

1. Buie DH. Empathy: its nature and limitations. JAm Psychoanal Assoc. 1981;29(2):281-307.

2. Coulehan J, Platt FW, Egener B, et al. "Let me see if I have this right ...": words that help build empathy. Ann Intern Med. 2001;135(3): 221-227.

3. Hojat M, Gonnella J, Mangione S, et al. The Jefferson Scale of Physician Empathy: development and preliminary psychometric data. Educ Psychol Meas. 2001;61:349-365.

4. Jha AK, Doolan D, Grandt D, Scott T, Bates DW. The use of health information technology in seven nations. Int J Med Inform. 2008; 77(12):848-854.

5. Zinn W. The empathic physician. Ann Intern Med. 1993;153(3): 306-312.

6. Falvo D, Tippy P. Communicating information to patients. Patient satisfaction and adherence as associated with resident skill. $J$ Fam Pract. 1988;26(6):643-647.

7. Hall JA, Roter DL, Katz NR. Meta-analysis of correlates of provider behavior in medical encounters. Med Care. 1988;26(7):657-675.

8. Kim SS, Kaplowitz S, Johnston MV. The effects of physician empathy on patient satisfaction and compliance. Eval Health Prof. 2004;27(3):237-251

9. Zachariae R, Pedersen CG, Jensen AB, Ehrnrooth E, Rossen PB, von der Maase H. Association of perceived physician communication style with patient satisfaction, distress, cancer-related self-efficacy, and perceived control over the disease. Br J Cancer. 2003;88(5):658-665.

10. Neumann M, Wirtz M, Bollschweiler E, et al. Determinants and patient-reported long-term outcomes of physician empathy in oncology: a structural equation modelling approach. Patient Educ Couns. 2007;69(1-3):63-75.

11. Mercer SW, Neumann M, Wirtz M, Fitzpatrick B, Vojt G. General practitioner empathy, patient enablement, and patient-reported outcomes in primary care in an area of high socio-economic deprivation in Scotland - a pilot prospective study using structural equation modeling. Patient Educ Couns. 2008;73(2):240-245.

12. Del Canale S, Louis DZ, Maio V, et al. The relationship between physician empathy and disease complications: an empirical study of primary care physicians and their diabetic patients in Parma, Italy. Acad Med. 2012;87(9):1243-1249.

13. Hojat M, Louis DZ, Markham FW, Wender R, Rabinowitz C, Gonnella JS. Physicians' empathy and clinical outcomes for diabetic patients. Acad Med. 2011;86(3):359-364.

14. Rakel DP, Hoeft TJ, Barrett BP, Chewning BA, Craig BM, Niu M. Practitioner empathy and the duration of the common cold. Fam Med. 2009;41(7):494-501.

15. Burns DD, Nolen-Hoeksema S. Therapeutic empathy and recovery from depression in cognitive-behavioral therapy: a structural equation model. J Consult Clin Psychol. 1992;60(3):441-449.

16. Spiro H. Commentary: the practice of empathy. Acad Med. 2009;84(9): $1177-1179$

17. Vedsted P, Heje HN. Association between patients' recommendation of their GP and their evaluation of the GP. Scand J Prim Health Care. 2008;26(4):228-234. 
18. Di Blasi Z, Harkness E, Ernst E, Georgiou A, Kleijnen J. Influence of context effects on health outcomes: a systematic review. Lancet. 2001;357(9258):757-762.

19. Anfossi M, Numico G. Empathy in the doctor-patient relationship. J Clin Oncol. 2004;22(11):2258-2259.

20. Hojat M, Louis DZ, Maio V, Gonnella JS. Empathy and health care quality. Am J Med Qual. 2013;28(1):6-7.

21. Hojat M, Vergare MJ, Maxwell K, et al. The devil is in the third year: a longitudinal study of erosion of empathy in medical school. Acad Med. 2009;84(9):1182-1191.

22. Stepien KA, Baernstein A. Educating for empathy. A review. J Gen Intern Med. 2006;21(5):524-530.

23. Hojat M. Empathy in Patient Care: Antecedents, Development, Measurement, and Outcomes. New York, NY, USA: Springer; 2007.

24. Stratton TD, Saunders JA, Elam CL. Changes in medical students emotional intelligence: an exploratory study. Teach Learn Med. 2008;20(3):279-284.

25. Sherman JJ, Cramer A. Measurement of changes in empathy during dental school. J Dent Educ. 2005;69(3):338-345.

26. Newton BW, Barber L, Clardy J, Cleveland E, O'Sullivan P. Is there hardening of the heart during medical school? Acad Med. 2008;83(3):244-249.

27. Newton B, Savidge M, Barber L, et al. Differences in medical students' empathy. Acad Med. 2000;75(12):1215.

28. Hojat M, Mangione S, Nasca TJ, et al. An empirical study of decline in empathy in medical school. Med Educ. 2004;38(9):934-941.

29. Diseker RA, Michielutte R. An analysis of empathy in medical students before and following clinical experience. J Med Educ. 1981;56(12) 1004-1010.

30. Chen DC, Kirshenbaum DS, Yan J, Kirshenbaum E, Aseltine RH Characterizing changes in student empathy throughout medical school. Med Teach. 2012;34(4):305-311.

31. Chen D, Lew R, Hershman W, Orlander J. A cross-sectional measurement of medical student empathy. J Gen Intern Med. 2007;22(10): 1434-1438.

32. Bellini LM, Baime M, Shea JA. Variation of mood and empathy during internship. JAMA. 2002;287(23):3143-3146.

33. Bellini LM, Shea JA. Mood change and empathy decline persist during three years of internal medicine training. Acad Med. 2005;80(2):164-167.

34. Rosen IM, Gimotty PA, Shea JA, Bellini LM. Evolution of sleep quantity, sleep deprivation, mood disturbances, empathy, and burnout among interns. Acad Med. 2006;81(1):82-85.

35. Magalhaes E, Salgueira AP, Costa P, Costa MJ. Empathy in senior year and first year medical students: a cross-sectional study. BMC Med Educ. 2011;11:52.

36. Kataoka HU, Koide N, Ochi K, Hojat M, Gonnella JS. Measurement of empathy among Japanese medical students: psychometrics and score differences by gender and level of medical education. Acad Med. 2009;84(9):1192-1197.

37. Hong M, Lee W, Park J, et al. Changes of empathy in medical college and medical school students: 1-year follow up study. BMC Med Educ. $2012 ; 12: 122$

38. Ward J, Schaal M, Sullivan J, Bowen ME, Erdmann JB, Hojat M. Reliability and validity of the Jefferson Scale of Empathy in undergraduate nursing students. J Nurs Meas. 2009;17(1):73-88.

39. Lee BK, Bahn GH, Lee WH, Park JH, Yoon TY, Baek SB. The relationship between empathy and medical education system, grades, and personality in medical college students and medical school students. Korean Journal of Medical Education. 2009;21(2):117.

40. Colliver J, Conlee M, Verhulst S, Dorsey K. Reports of the decline of empathy during medical education are greatly exaggerated: a re-examination of the research. Acad Med. 2010;85(4):588-593.

41. Aomatsu M, Otani T, Ban N, van Dalen J. Medical students' and residents' conceptual structure of empathy: a qualitative study. Educ Health (Abingdon). 2013;26(1):4-8.
42. Morse JM, Anderson G, Bottorff JL, et al. Exploring empathy: a conceptual fit for nursing practice. J Nurs Scholarsh. 1992;24(4):273-280.

43. Larson E, Yao X. Clinical empathy as emotional labor in the patientphysician relationship. JAMA. 2005;293(9):1100-1106.

44. Greenberg LW, Ochsenschlager D, O’Donnell R, Mastruserio J, Cohen GJ. Communicating bad news: a pediatric department's evaluation of a simulated intervention. Pediatrics. 1999;103(6 Pt 1):1210-1217.

45. Testerman JK, Morton KR, Loo LK, Worthley JS, Lamberton HH. The natural history of cynicism in physicians. Acad Med. 1996; 71(Suppl 10):S43-S45.

46. Fernández-Olano C, Montoya-Fernández J, Salinas-Sánchez AS. Impact of clinical interview training on the empathy level of medical students and medical residents. Med Teach. 2008;30(3):322-324.

47. Wear D, Zarconi J, Garden R, Jones T. Reflection in/and writing: pedagogy and practice in medical education. Acad Med. 2012;87(5): 603-609.

48. Finestone HM, Conter DB. Acting in medical practice. Lancet. 1994;344(8925):801-802.

49. Hemmerdinger JM, Stoddart SD, Lilford RJ. A systematic review of tests of empathy in medicine. BMC Med Educ. 2007;7:24.

50. Hojat M, Mangione S, Nasca TJ, Gonnella JS, Magee M. Empathy scores in medical school and ratings of empathic behavior in residency training 3 years later. J Soc Psychol. 2005;145(6):663-672.

51. Winefield H, Chur-Hansen A. Evaluating the outcome of communication skill teaching for entry-level medical students: does knowledge of empathy increase? Med Educ. 2000;34:90-94.

52. Jefferson Medical College. Jefferson Scale of Empathy. 2013. Available from: http://www.jefferson.edu/jmc/crmehc/medical_education/jspe. html. Accessed July 19, 2013.

53. Cronnach L, Meehl P. Construct validity in psychological tests. Psychol Bull. 1955;52(4):281-302.

54. Cheng JF, Lai YM, Livneh H, Tsai TY. [Establishing reliability and validity of the Chinese version of the Jefferson scale of empathy (healthcare providers version)]. Hu Li Za Zhi. 2011;58(2):41-48. Chinese.

55. Paro H, Daud-Gallotti R, Tibério I, Pinto R, Martin M. Brazilian version of the Jefferson Scale of Empathy: psychometric properties and factor analysis. BMC Med Educ. 2012;12:73.

56. Rahimi-Madiseh M, Tavakol M, Dennick R, Nasiri J. Empathy in Iranian medical students: a preliminary psychometric analysis and differences by gender and year of medical school. Med Teach. 2010;32(11): e471-e478.

57. Roh MS, Hahm BJ, Lee DH, Suh DH. Evaluation of empathy among Korean medical students: a cross-sectional study using the Korean Version of the Jefferson Scale of Physician Empathy. Teach Learn Med. 2010;22(3):167-171.

58. Shariat SV, Habibi M. Empathy in Iranian medical students: measurement model of the Jefferson Scale of Empathy. Med Teach. 2013;35(1): e913-e918.

59. Nunes P, Williams S, Sa B, Stevenson K. A study of empathy decline in students from five health disciplines during their first year of training. Int J Med Educ. 2011;2:12-17.

60. Di Lillo M, Cicchetti A, Lo Scalzo A, Taroni F, Hojat M. The Jefferson Scale of Physician Empathy: preliminary psychometrics and group comparisons in Italian physicians. Acad Med. 2009;84(9): 1198-1202.

61. Kliszcz J, Nowicka-Sauer K, Trzeciak B, Nowak P, Sadowska A. Empathy in health care providers - validation study of the Polish version of the Jefferson Scale of Empathy. Adv Med Sci. 2006;51: 219-225.

62. Van Winkle LJ, Fjortoft N, Hojot M. Impact of a workshop about aging on the empathy scores of pharmacy and medical students. Am J Pharm Educ. 2012;76(1):9.

63. Hojat M, Axelrod D, Spandorfer J, Mangione S. Enhancing and sustaining empathy in medical students. Med Teach. 2013;35(12): 996-1001. 
Advances in Medical Education and Practice

Dovepress

\section{Publish your work in this journal}

Advances in Medical Education and Practice is an international, peerreviewed, open access journal that aims to present and publish research on Medical Education covering medical, dental, nursing and allied health care professional education. The journal covers undergraduate education, postgraduate training and continuing medical education

including emerging trends and innovative models linking education, research, and health care services. The manuscript management system is completely online and includes a very quick and fair peer-review system. Visit http://www.dovepress.com/testimonials.php to read real quotes from published authors.

Submit your manuscript here: http://www.dovepress.com/advances-in-medical-education-and-practice-journal 